\title{
Stigma, Persecution, and Neglect: HIV in Russian Men Who Have Sex with Men
} Twigg J*

\author{
Department of Political Science, Virginia Commonwealth University, USA
}

*Corresponding author: Twigg J, Department of Political Science, Virginia Commonwealth University, USA, E-mail: jtwigg@vcu.edu

Citation: Twigg J (2016) Stigma, Persecution, and Neglect: HIV in Russian Men Who Have Sex with Men. J Aids Hiv Infec 2(1): 102. doi: 10.15744/2454-499X.2.102

Received Date: April 28, 2016 Accepted Date: July 06, 2016 Published Date: July 08, 2016

Russia's HIV epidemic has received considerable academic and mainstream press attention in recent weeks, following Moscow's fifth annual Eastern Europe and Central Asia AIDS Conference in March, and its Federal AIDS Center's announcement in January that the number of HIV cases in the country had broken the one million mark. This conversation - laced with uncertain data and possibly hyperbolic speculation about the epidemic's expansion beyond "traditional" high-risk groups and their sexual partners focuses still, and appropriately, on injection drug users as the main vulnerable population.

No risk group in Russia, however, is more understudied and persecuted than men who have sex with men (MSM). Conservative attitudes in the country have historically stigmatized and marginalized this community, culminating in 2013 legislation banning the "promotion of homosexuality" - a broadly worded law whose interpretation and enforcement covers a wide range of identities and behaviors. Fear of exposure means that the official statistics putting MSM at about 3\% of Russia's HIV-positive population are certainly, and most likely vastly, understated; these men are unlikely to report exactly how they became infected.

Russia's political leadership currently exhibits zero interest in correcting the marginalization of MSM (and those at risk for HIV, in general). Sadly, public opinion exerts very little pressure for change. Instead, Russian legislators seek calculated political gain through proposals to require HIV testing for couples planning to marry, or to ban foreign-made condoms in an effort to make people "more disciplined, strict, and discriminating in choosing partners" and perhaps make a dent in the country's low birth ratedriven demographic crunch $[1,2]$. Public investments in antiretroviral therapy (ART) are insufficient; it's estimated that treatment currently covers about $20-30 \%$ of those in need, compared with about $60 \%$ globally. Aggressive import substitution policies in the pharmaceutical industry, prompted by Western sanctions over the conflict in Ukraine, have negatively impacted the quality and quantity of available drugs.

Although the government announced a doubling of HIV/AIDS funding in October of 2015, hiking spending from US\$ 300 million to US\$ 600 million for 2016, the resource-to-need ratio remains miniscule. The Russian government crackdown on international support for non-governmental organizations since 2012 - and the threat of a "foreign agent" tag on any NGO associating with Western partners - has prompted the Global Fund and other external financiers to pull out. Many domestic HIV/AIDS services NGOs have had no choice but to alter course toward politically "safer" activities or close their doors altogether. One result: prevention interventions targeted at MSM (and IDUs, and sex workers) have plummeted below even their previously low levels.

The impact is clear. One recent study, covering 1,376 Muscovite MSM recruited through respondent-driven sampling between October 2010 and April 2013, found 184, or 15.6\% of the total, to be infected with HIV, and of those, only $23.4 \%$ aware of their infection, $16.9 \%$ linked to care, $8.7 \%$ currently on ART, and $4.4 \%$ having an undetectable viral load [3]. This alarming lack of information about their own HIV status was more likely among respondents who were associated with bisexual identity (who may not access HIV prevention information targeted at men who identify as gay), who had a larger number of sex partners, and for whom HIV testing was required as a condition of employment. The latter risk factor points to the common practice of purchasing negative HIV test results without actually undergoing testing.

Too often, discussions of HIV and MSM in the Russian context begin and end with a lament that it's so difficult to identify and reach them. There are options, however, for introducing HIV testing and treatment opportunities to Russian MSM. HIV self-testing and CD4 point-of-care tests - which provide a CD4 result the same day as an HIV diagnosis, allowing expedited initiation of ART - have produced increased status awareness and access to appropriate care in other settings where stigma is a barrier and resources are limited [4]. And there are methods that work for reaching Russian MSM to deliver prevention messages, testing services, and access to care: through their social networks. 
Informal social networks have been unusually important in Russian society dating back to the Soviet period, when government authorities were rightly seen not only as untrustworthy but often threatening. Most people relied on tight personal networks for social support and as sources of information and scarce consumer goods. Since the Soviet collapse, these networks have evolved into widespread channels for access and influence along virtually every avenue of society, and it has been demonstrated that they can be used to influence risk behaviors among MSM. A 2007-2012 study of ten MSM networks in St. Petersburg, Russia, identifying MSM social "seeds" (centers of social attention) and their first-, second-, and third-ring contacts and then training/guiding the "seeds" to convey HIV prevention advice to other network members, showed significant reductions versus comparison groups in unprotected anal intercourse, including with a non-main partner and with multiple partners. Biological incidence of HIV and sexually transmitted infections at twelve months was $15 \%$ in comparison networks but only $9 \%$ in the intervention networks [5].

Clearly, there are ways to reach this underserved population, with harnessing of social networks at the top of the list. But political will and funding are not only scarce, but absent. Until MSM become a legitimized public health priority, Russia's unwelcome distinction -- home to one of the few remaining expanding HIV epidemics on the planet -- is likely to persist.

\section{References}

1 Former Chief Sanitary Inspector Gennady Onishchenko, quoted in Kellan Howell, Russia Pushes Ban on Foreign Condoms to Make Lovers 'More Disciplined. Washington Times, August 6, 2015.

2. Tejas A (2015) Russian Lawmakers Advocate Manadatory HIV Testing Plan for Couples Seeking To Marry. Int Business Times, August 13.

3. Wirtz AL, Zelaya CE, Latkin C, Peryshkina A, Galai N, et al. (2016) The HIV Care Continuum among Men Who Have Sex with Men in Moscow, Russia: A Cross-Sectional Study of Infection Awareness and Engagement in Care. Sex Transm Infect 92: 161-7.

4. Hyle EP, Jani IV, Lehe J, Su AE, Wood R, et al. (2014) The Clinical and Economic Impact of Point-of-Care CD4 Testing in Mozambique and other ResourceLimited Settings: A Cost-Effectiveness Analysis. PLoS Med 11: e1001725.

5. Amirkhanian YA, Kelly JA, Takacs J, McAuliffe TL, Kuznetsova AV, et al. (2015) Effects of a Social Network HIV/STD Prevention Intervention for MSM in Russia and Hungary: A Randomized Controlled Trial. AIDS 29: 583-93.

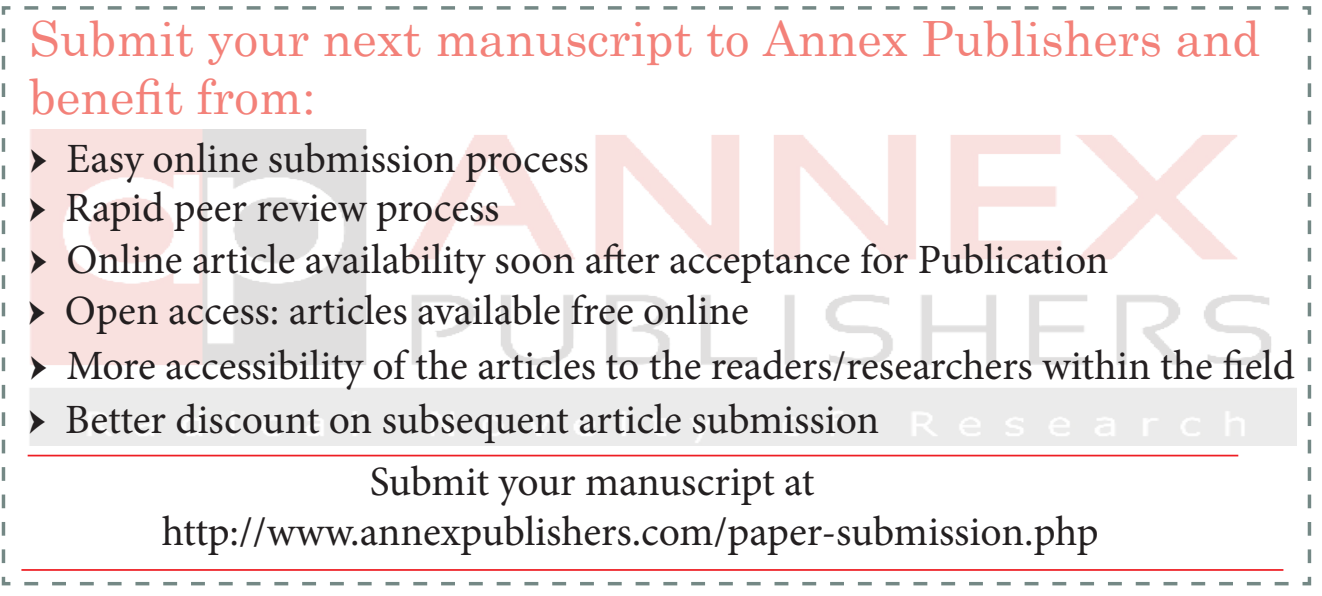

